\section{PERFIL DOS PROFESSORES DA REDE ESTADUAL DE ENSINO DE MINAS GERAIS}

\author{
Débora Fernandes de Miranda*
}

* Doutora em Educação pela UFMG. Docente da Fundação João Pinheiro.

Este artigo apresenta o perfil dos professores concursados e temporários do Ensino Fundamental e do Ensino Médio da Rede Estadual de Ensino de Minas Gerais (REE-MG). Para traçar esse perfil, foi desenvolvido um estudo de caráter quantitativo com base nos dados do Cadastro de Profissional Escolar do Censo Escolar do INEP de 2015. O objetivo da pesquisa foi analisar o perfil sociodemográfico, a escolaridade e algumas características do trabalho desses docentes e identificar possíveis diferenças entre professores concursados e temporários. Os resultados da pesquisa contribuem para ampliar a compreensão sobre quem são os professores da REE-MG e fornecer subsídios para a elaboração de políticas públicas que visem a valorização dos docentes e a melhoria da educação no estado.

Palavras-chave: Profissão Docente. Professores Concursados. Professores Temporários. Rede Estadual de Ensino de Minas Gerais.

\begin{abstract}
This paper introduces the profile of the temporary teachers and the civil servant teachers of Elementary, Secondary, and High Schools from the Public Education System of the State of Minas Gerais. To develop this profile, we carried out a quantitative study based on the data from the School Staff Registration Form of the 2015 School Census. The objective of the study was to analyze the sociodemographic profile, the education level, and some of the characteristics of the work of these teachers. Furthermore, we searched to identify possible differences between the profile of temporary and civil servant teachers. The results of the study contribute to broaden the understanding of the profile of the teachers from the Public Education System of the State of Minas Gerais and to support the development of public policies that aim at improving teachers' status and the education in the state.
\end{abstract}

Keywords: Teaching Profession. Civil Servant Teachers. Temporary Teachers. Public Education System of the State of Minas Gerais. 


\section{INTRODUÇÃO}

A educação é considerada uma área fundamental para o desenvolvimento socioeconômico e político de um país e, ao redor do mundo, tem sido cada vez mais valorizada como uma maneira de construir uma sociedade mais igualitária. Seguindo a tendência de valorização da educação, a agenda educacional brasileira, pautada pelo Plano Nacional de Educação do Brasil (PNE) (2011-2020) (BRASIL, 2010), apresenta como desafios dessa área a melhoria do ensino e a valorização dos profissionais da educação. De acordo com dados disponíveis no site do Ministério da Educação (MEC) (BRASIL, 2015), 98,2\% das crianças entre 6 e 14 anos de idade estão matriculadas no Ensino Fundamental e a meta é melhorar as taxas de matrículas do Ensino Infantil e do Ensino Médio. É um inegável avanço termos conseguido matricular tantas crianças e jovens na escola. Porém, os resultados dos estudantes brasileiros em avaliações nacionais e internacionais ${ }^{1}$, indicam que, apesar de estarem matriculados no ensino regular, nossos alunos têm graves lacunas em sua formação escolar e que a oferta de um ensino de qualidade ainda representa um obstáculo a ser superado no país, a começar por aspectos relacionados ao professor do ensino básico, como sua formação, suas práticas e sua permanência (ou não) na carreira docente.

A literatura internacional e nacional na área da Sociologia da Educação indica uma influência marcante da origem socioeconômica e cultural dos estudantes no desempenho escolar dos mesmos. Isso significa que alunos com menos recursos sociais, econômicos e culturais tendem a obter resultados piores nas escolas, enquanto alunos providos de mais recursos tendem a ter melhor desempenho (BOURDIEU, 2003,;

\footnotetext{
${ }^{1}$ O último Índice de Desenvolvimento da Educação Básica (IDEB) (BRASIL, 2016b) indica que os resultados dos alunos brasileiros não têm apresentado avanços significativos e estão estagnados em patamares bastante baixos. Na última edição do PISA - Programme for International Student Assessment - (BRASIL, 2016a), o escore médio dos alunos brasileiros não evoluiu em relação à edição de 2012, permanecendo bem abaixo da média dos estudantes dos países da OCDE. No ranking dos 70 países participantes, o Brasil ficou na $65^{\mathrm{a}}$ posição.
} 
2008). No entanto, pesquisas demonstram que outros fatores além das famílias podem impactar positivamente o percurso escolar desses alunos e que, na esfera da escola, o professor desempenha um papel fundamental no sentido de melhorar a aprendizagem desses jovens (BRESSOUX, 2003, ORGANIZAÇÃO PARA A COOPERAÇÃO E DESENVOLVIMENTO ECONÔMICO, 2005).

Relatório da OCDE (2005) indica que as políticas educativas atuais têm dado grande ênfase ao professor e ao trabalho docente como fatores essenciais para a oferta de um ensino de qualidade, pois, dentre as variáveis potencialmente abertas à influência das políticas públicas na área de educação, aquelas referentes aos professores e às suas práticas em sala de aula podem ser consideradas as de maior impacto para o desempenho dos estudantes. No referido estudo, a OCDE (2005) ressalta a importância das políticas públicas para os docentes e enfatiza que a qualidade do ensino é vital para uma melhor aprendizagem dos alunos. De acordo com o relatório, os professores representam um contingente significativo de profissionais para mercado de trabalho e para o orçamento das escolas o que, por si só, já justificaria esforços para elaborar e implantar políticas mais eficazes. Além disso, políticas relacionadas aos docentes estão sendo intensificadas mundialmente devido a demandas econômicas e sociais que requerem uma escola que proporcione os fundamentos para uma aprendizagem permanente.

Apesar de fundamental para o desenvolvimento da educação no país, pesquisas apontam que a profissão docente passa por uma crise composta por diversos aspectos, tais como a baixa atratividade da carreira, a baixa demanda por cursos de licenciatura, a evasão de professores do ensino básico, dentre outros. Gatti, Barretto e André (2011) indicam a existência de grandes dificuldades em se elaborar e implementar políticas docentes para atrair, formar e manter nas escolas os melhores professores (GATTI; BARRETTO; ANDRÉ, 2011) o que acaba gerando impactos negativos na aprendizagem e no desempenho dos alunos. Múltiplos fatores compõem um cenário pouco atraente da 
carreira docente, afetando o recrutamento de alunos para os cursos de licenciatura e Pedagogia, assim como a permanência de professores atuando no ensino básico. Dentre eles, podem ser citados o pouco prestígio social da profissão, baixos salários, condições de trabalho por vezes degradantes, indisciplina e violência na escola (GATTI et al., 2009; GATTI; BARRETTO, 2009).

Tendo em vista a centralidade do papel do professor para a construção de uma educação de melhor qualidade, este artigo traz os resultados de um estudo que teve por objetivo traçar o perfil dos professores do Ensino Fundamental e do Ensino Médio da Rede Estadual de Ensino de Minas Gerais (REE-MG). Quem é esse professor? Qual sua formação? Quais são algumas das características relevantes de seu trabalho? Existem diferenças entre o perfil dos professores concursados e dos temporários? Essas foram algumas das questões norteadoras desse estudo que buscou conhecer quem são os docentes da rede estadual de ensino mineira do ponto de vista sociodemográfico, de sua escolaridade e de seu trabalho. Para fazer o levantamento do perfil desse professor, foi desenvolvido um estudo de caráter quantitativo com base nos microdados do Cadastro de Profissional Escolar do Censo Escolar do Instituto Nacional de Estudos e Pesquisas Educacional (INEP 2015). Com base na análise aqui apresentada, pretendemos aprofundar a compreensão sobre o perfil do professor da REE-MG e contribuir para ampliar o debate referente à profissão docente tanto no no nível estadual quanto no nível nacional.

Primeiramente, o artigo apresentará a base teórica que norteia a análise dos dados desenvolvida para o estudo, discutindo os conceitos de efeito-escola e efeito-professor. Em seguida, será apresentado o desenho metodológico do estudo e, posteriormente, serão feitas a exposição e a análise dos dados. Finalmente, serão feitas considerações acerca da pesquisa e de seus resultados.

\section{PROFESSORES FAZEM DIFERENÇA?}


Apesar da inegável influência da origem social no desempenho escolar, estudos indicam que outros fatores, além do contexto familiar e do capital econômico e cultural herdado, podem influenciar a aprendizagem dos alunos e o professor é um deles. Pesquisas sobre o efeito-escola e o efeito-professor buscam compreender as variações de aquisições de alunos com perfil socioeconômico semelhante em função da escola ou da sala de aula em que estudam.

De acordo com estudo de Hanushek (2002), as diferenças entre professores são significativas e indicam que eles têm grande potencial para influenciar a aprendizagem e o desempenho dos estudantes. Estudando o "efeito-professor" a partir de resultados de provas parametrizadas de alunos do segundo ao sexto ano do Ensino Fundamental nos Estados Unidos, o pesquisador conclui que a diferença estimada entre o desempenho anual de alunos da mesma série e de mesmo perfil social pode corresponder a um ano acadêmico dependendo do professor. Segundo o pesquisador, esse resultado demonstra que o desempenho dos professores varia da maneira muito significativa e tem impactos diretos para aprendizagem dos estudantes. No entanto, o Hanushek ressalta a dificuldade em identificar os atributos que fazem com que certos professores tenham desempenho melhor que outros. Os modelos tradicionais de análise sobre o efeito-professor baseiam-se em um número limitado de atributos mensuráveis, como número de alunos por sala de aula e grau de escolaridade dos professores, e os resultados de sua pesquisa demonstraram a existência de somente uma variável significativa, relacionada ao tempo de experiência na docência.

Darling-Hammond (2000) conduziu uma pesquisa que analisou fontes de dados distintas: questionários sobre políticas educacionais de 50 estados dos Estados Unidos, estudos de casos, e dois levantamentos nacionais - um sobre escolas e funcionários, outro sobre avaliação educacional. O objetivo do estudo foi investigar a relação entre a qualificação dos professores e outros recursos escolares, e o desempenho 
escolar dos alunos nos Estados Unidos. Os resultados da pesquisa sugerem que as políticas de investimento na formação dos professores estão diretamente relacionadas à melhoria no desempenho escolar. As análises quantitativas desse estudo indicam que formação e qualificação dos professores, assim como tempo de experiência docente, são os fatores com maior impacto nos resultados das provas de leitura e matemática, tanto em simulações com controle das variáveis renda e idioma (devido ao grande número de imigrantes no país) como em simulações sem o controle dessas variáveis. Outro resultado importante dessa pesquisa diz respeito aos reflexos positivos de políticas de incentivo a qualificação dos professores, desenvolvimento profissional e de recrutamento para melhorar o desempenho dos docentes e, consequentemente, a aprendizagem dos alunos.

Na mesma linha, Rivkin, Hanushek e Kain (2005) pesquisaram os impactos de escolas e professores sobre o desempenho de estudantes e uma das conclusões da investigação indica que os ganhos no desempenho dos estudantes são relacionados a características observáveis do professor e da escola, mas que os efeitos são geralmente pequenos e concentrados entre os alunos mais jovens. Em relação aos recursos da escola, os autores demonstram que:

a) não há evidência que cursos de mestrado melhorem o desempenho dos docentes;

b) os professores melhoram o desempenho consideravelmente no primeiro ano da carreira e nos dois anos subsequentes, mas não há evidência de melhora no desempenho depois dos três primeiros anos;

c) o efeito do número de alunos por sala de aula é significativo para o desempenho em matemática e leitura, mas diminui à medida que os alunos ficam mais velhos e passam para as séries finais de escolarização. Os resultados apontam também que os custos de uma redução de dez alunos nas classes são menores que os custos 
para melhorar a qualidade do professor.

Além dos reflexos no percurso escolar dos estudantes, os resultados da pesquisa de Chetty, Friedman e Rockoff (2011) mostraram que os impactos positivos de um bom professor podem se perpetuar ao longo da vida de seus alunos. Segundo os pesquisadores, estudantes investigados que tiveram professores com maior valor-agregado ${ }^{2}$ apresentaram maiores chances de frequentar uma universidade, ter melhores salários, morar em bairros mais valorizados e economizar mais para a aposentadoria.

Assim como demonstrado pela literatura internacional, no Brasil, resultados de pesquisas sobre o desempenho dos alunos da educação básica nas provas do Sistema de Avaliação da Educação Básica (SAEB) ${ }^{3}$ indicam que há uma grande variação nos resultados de escolas de um mesmo sistema que atendem alunos de perfil socioeconômico parecidos. Esse dado sugere que a escola frequentada pelo aluno pode influenciar seu percurso escolar e matiza os reflexos do background familiar no desempenho dos estudantes (BROOKE; SOARES, 2008).

Em uma pesquisa de caráter quantitativo, Silva e Matos (2012) analisaram dados do Programa de Avaliação da Rede Pública de Educação Básica (PROEB) de Minas Gerais, relacionando os resultados das avaliações em língua portuguesa e matemática com informações obtidas pelo questionário aplicado aos alunos sobre características socioculturais, ambiente escolar e práticas pedagógicas de seus professores. A pesquisa apresenta importantes resultados. Um deles é que nas escolas em que houve maior incidência de indisciplina, a proficiência dos alunos foi baixa, demonstrando, assim, a relação direta entre

\footnotetext{
${ }^{2}$ De acordo com a pesquisa citada, o valor-agregado do professor é determinado pelas notas de seus alunos em provas parametrizadas (CHETTY; FRIEDMAN; ROCKOFF, 2011).

3 SAEB: Sistema de Avaliação da Educação Básica - sistema de monitoramento do ensino, cuja população de referência soa os alunos brasileiros do ensino regular, em escolas públicas e privadas, urbanas e rurais, que frequentam o último ano do Ensino Fundamental 1 (quinto ano), o último ano do Ensino Fundamental 2 (nono ano) e o terceiro ano do Ensino Médio de todas as Unidades da Federação.
} 
comportamentos de indisciplina e baixo rendimento escolar. Outro resultado demonstrou uma baixa relação entre nível socioeconômico e indisciplina, o que sugere que a origem social dos alunos não é elemento principal para compreender a indisciplina. Esse resultado contraria a ideia corrente, presente não só no discurso de professores e diretores como também na literatura acadêmica, que associa origem social a problemas de disciplina. O último resultado diz respeito às práticas pedagógicas dos professores. A pesquisa sugere que existe uma relação entre as práticas dos professores e a proficiência dos alunos devido à maior ou menor capacidade do professor em produzir um ambiente com disciplina em sala de aula. Esse resultado sugere que as práticas pedagógicas dos professores podem ser propiciadoras de um processo de ensino e aprendizagem de melhor (ou pior) qualidade.

\section{DESENHO DA PESQUISA}

O estudo desenvolvido é de caráter quantitativo e teve como base o levantamento de dados referentes ao Cadastro de Profissional Escolar do Censo Escolar do INEP preenchido pelos professores em 2015. O Censo Escolar é, um levantamento de dados estatísticos educacionais, feito com a colaboração das secretarias estaduais e municipais de educação e com a participação de todas as escolas públicas e privadas do país. O preenchimento dos dados é obrigatório tanto para instituições públicas quanto privadas e as informações acerca do cenário educacional subsidiam a elaboração de políticas públicas e ações que têm por objetivo a melhoria da educação no país.

Como os dados são obtidos por meio de um levantamento nacional, primeiramente, foi necessário filtrar as informações específicas referentes, ao estado de Minas Gerais, à Rede Estadual de Ensino e aos professores de Ensino Fundamental e de Ensino Médio. Em seguida, os dados foram descritos e analisados tendo como referência a literatura científica do campo educacional. A análise foi desenvolvida a partir de 
três eixos. No primeiro, são apresentados dados sobre o perfil demográfico dos docentes; o segundo eixo refere-se a dados sobre a formação dos docentes; o último apresenta dados relativos à docência.

\section{QUEM SÃO OS PROFESSORES DA REE-MG? APRESENTAÇÃO E ANÁLISE DOS DADOS}

Antes de iniciar a análise do perfil dos professores da REE-MG, é necessário esclarecer a natureza das diferentes contratações dos professores do estado. Existem três tipos de contratação de docentes para a REE-MG: a primeira é feita por meio de concurso público estadual e, quando aprovados, os docentes tornam-se professores efetivos, ou seja, servidores públicos estaduais. Todavia, para substituir os efetivos que se afastam do trabalho por algum motivo, como, por exemplo, situações de ajustamento funcional ou licença médica, e garantir a continuidade das aulas, é permitida a contratação temporária de docentes, chamados de professores designados. O terceiro agrupamento é formado por aqueles que tendo sido professores designados durante determinado tempo, tornaram-se efetivos no serviço público estadual por meio de mecanismos legais, como a Lei 100 (MINAS GERAIS, 2007), sem terem realizado um concurso público. Em princípio, esses professores efetivados possuiriam vínculo de trabalho estável, tal como os professores efetivos. No entanto, no final de 2015, a Lei 100 foi declarada inconstitucional pelo Supremo Tribunal Federal (STF) e os professores efetivados perderam o vínculo de trabalho estável que tinham no serviço público estadual. É possível afirmar que atualmente o número de professores da REE-MG com vínculo estável diminuiu, já que os docentes efetivados voltaram a ser temporários, e que o número de professores designados (que possuem contratos temporários) aumentou. Esse movimento foi descrito por Amorim e Barreiros (2017), que o denominaram superdesignação. As pesquisadoras apontam para um cenário em que a quase totalidade dos professores da REE-MG é 
composta por professores com contratos de trabalho precários.

Os dados analisados aqui se referem ao Cadastro do Profissional Escolar em Sala de Aula do Censo Escolar do INEP do ano de 2015. No cadastro, o item referente à situação funcional dos docentes apresenta quatro opções:

a) concursado, efetivo, estável;

b) contrato temporário; c) contrato terceirizado;

d) contrato CLT. Para traçar o perfil dos docentes e desenvolver a análise desta pesquisa, optou-se por categorizar os professores da REE-MG em dois agrupamentos: professores concursados - que englobam professores efetivos e os antigos efetivados, e professores temporários - os professores designados. Os dados foram coletados antes da queda da Lei 100 e, atualmente, como os efetivados não possuem mais uma situação funcional estável, o número de temporários sofreu um incremento. Nesse contexto, poderíamos imaginar que os dados usados neste artigo não seriam adequados para traçar o perfil do professor da REE-MG. As diferenças nos dados, porém, não invalidam o perfil traçado neste estudo, pois elas não alteraram o perfil dos docentes efetivos e temporários de modo significativo. Como poderá ser visto ao longo do desenvolvimento da análise, os professores efetivos e temporários apresentam perfis bastante semelhantes em vários aspectos. Além disso, como pode ser observado no gráfico abaixo, o número de professores temporários já era maior que o de efetivos mesmo antes da queda da Lei 100. Em 2015, a REEMG possuía um total de 91.387 professores, sendo que mais da metade deles - 48.903 era composta por professores temporários $(53,5 \%)$ e $42.484(46,5 \%)$ eram professores concursados. 


\section{Gráfico 1 - Porcentagem de professores concursados e temporários da REE-MG}

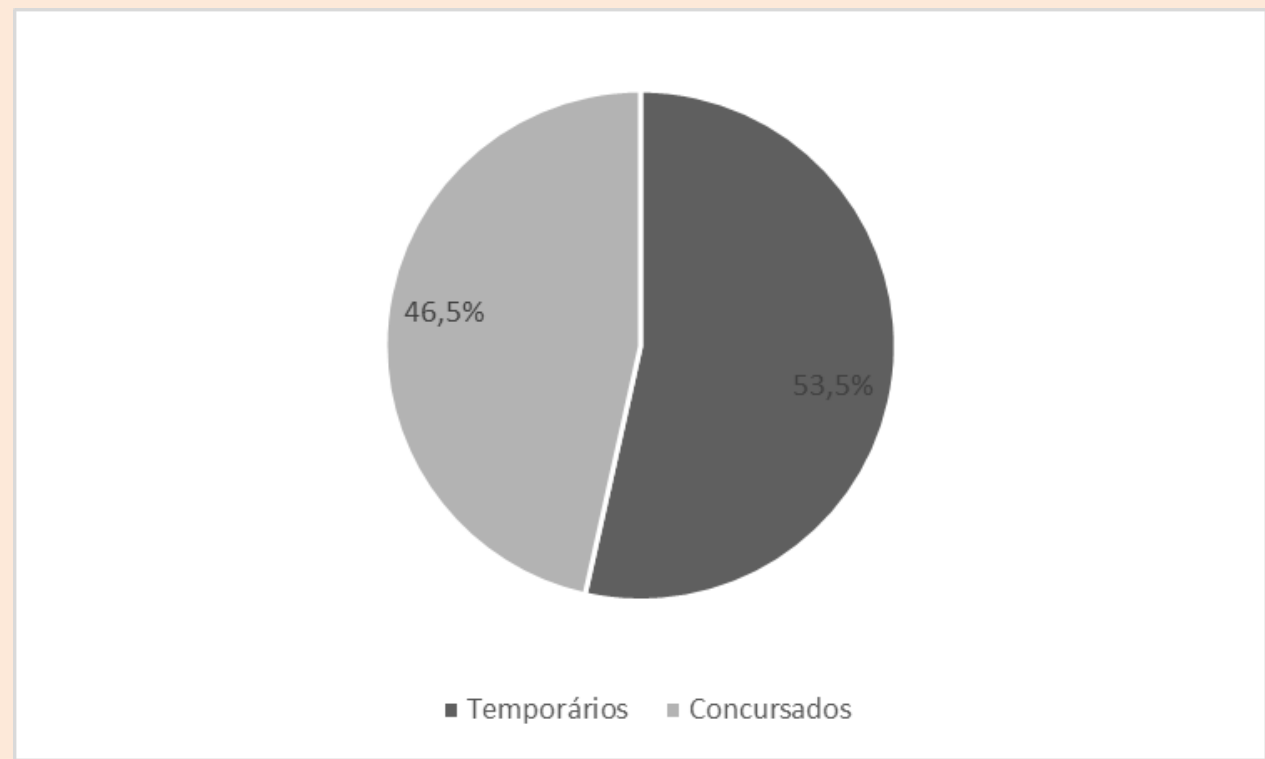

Fonte: Elaborado pela autora a partir dos dados do Censo Escolar do INEP 2015.

De acordo com o Plano Nacional de Educação (BRASIL, 2014), uma das estratégias para a valorização dos profissionais docente é ter, até o início do terceiro ano de vigência do plano, pelo menos $90 \%$ de professores com cargos efetivos nas redes públicas de educação básica. Se antes da queda da Lei 100 a situação da REE-MG já representava um enorme desafio para as políticas públicas de valorização do profissional docente no estado, é possível afirmar que a situação atual tornou-se crítica.

\subsection{Perfil demográfico}

Neste item, serão apresentados dados relativos a sexo, raça e faixa etária dos docentes da REE-MG. No que tange ao sexo, os professores da REE-MG seguem a tendência da categoria dos profissionais docentes, composta majoritariamente por mulheres: $77,4 \%$ dos professores temporários são mulheres e $22,6 \%$ são homens. Os professores concursados apresentam uma porcentagem um pouco maior de mulheres: são $78,9 \%$ mulheres e $21,6 \%$ homens. 
Gráfico 2 - Professores da REE - MG segundo sexo

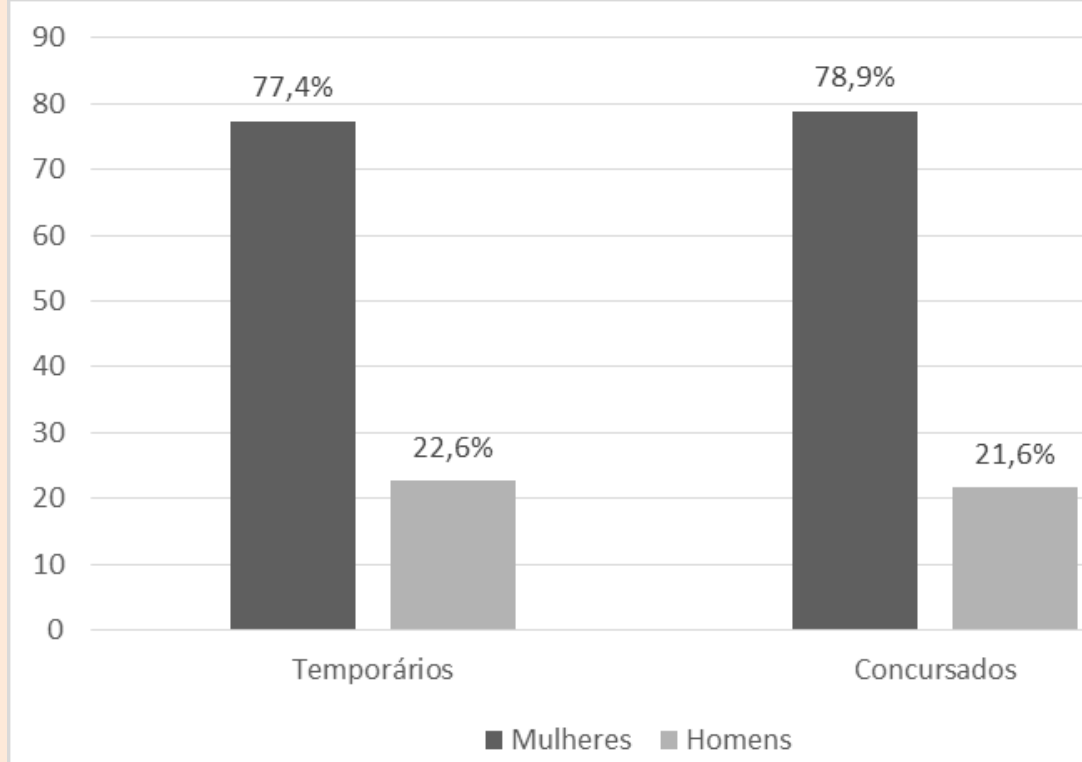

Fonte: Elaborado pela autora a partir dos dados do Censo Escolar do INEP 2015.

Esses dados estão em consonância com o perfil nacional traçado por Gatti e Barretto (2009). Segundo os dados apresentados pelas autoras, com base na PNAD de 2006, a categoria dos professores no Brasil é composta basicamente por mulheres: $83,1 \%$. A docência parece ser uma profissão de mulheres também em outros países. De acordo com a OCDE (2005), mais da metade dos países do grupo possui acima de $80 \%$ de mulheres trabalhando como professoras na educação básica e, segundo o relatório, a tendência é que esse número aumente, pois os professores homens estão concentrados na faixa de idade mais velha e estão próximos da aposentadoria e há menos homens jovens entrando na profissão docente.

A OCDE (2005) elenca algumas possíveis explicações para essa feminização: o salário dos professores em geral é menor quando comparado ao de outras profissões, principalmente para homens; existem fatores culturais que constroem o estereótipo da profissão docente como sendo um trabalho para mulheres, especialmente nos anos iniciais da escolarização. Mesmo em países em que a profissão docente é valorizada, como na Finlândia e na Irlanda, o número de mulheres professoras supera o de homens. Uma possível razão para isso é, segundo 
a OCDE (2005), o fato de que meninos tendem a apresentar desempenho escolar pior que meninas e que, portanto, existe uma proporção menor de candidatos do sexo masculino com a qualificação necessária para entrar na profissão docente.

Em relação à raça dos docentes da REE-MG, optamos por seguir a nomenclatura usada por Gatti e Barretto (2009): não-brancos e brancos. Os não-brancos agregam aqueles que se autodeclararam pretos, pardos e indígenas e brancos agregam brancos e amarelos. Ainda que a porcentagem de porcentagem de docentes que optaram por não declarar sua cor tenha sido alta, 18,1\% e 17,6\% para temporários e concursados, respectivamente, os dados levantados são bastante significativos. Observando o gráfico 3 é possível identificar que, entre os professores concursados, a porcentagem de professores autodeclarados não-brancos é de $40,3 \%$ e de professores autodeclarados brancos é de $42,1 \%$. Vale notar que entre os temporários, o número de docentes autodeclarados nãobrancos supera os brancos: são $42,1 \%$ de não-brancos e $39,8 \%$ de brancos.

\section{Gráfico 3 - Professores da REE-MG segundo Raça}

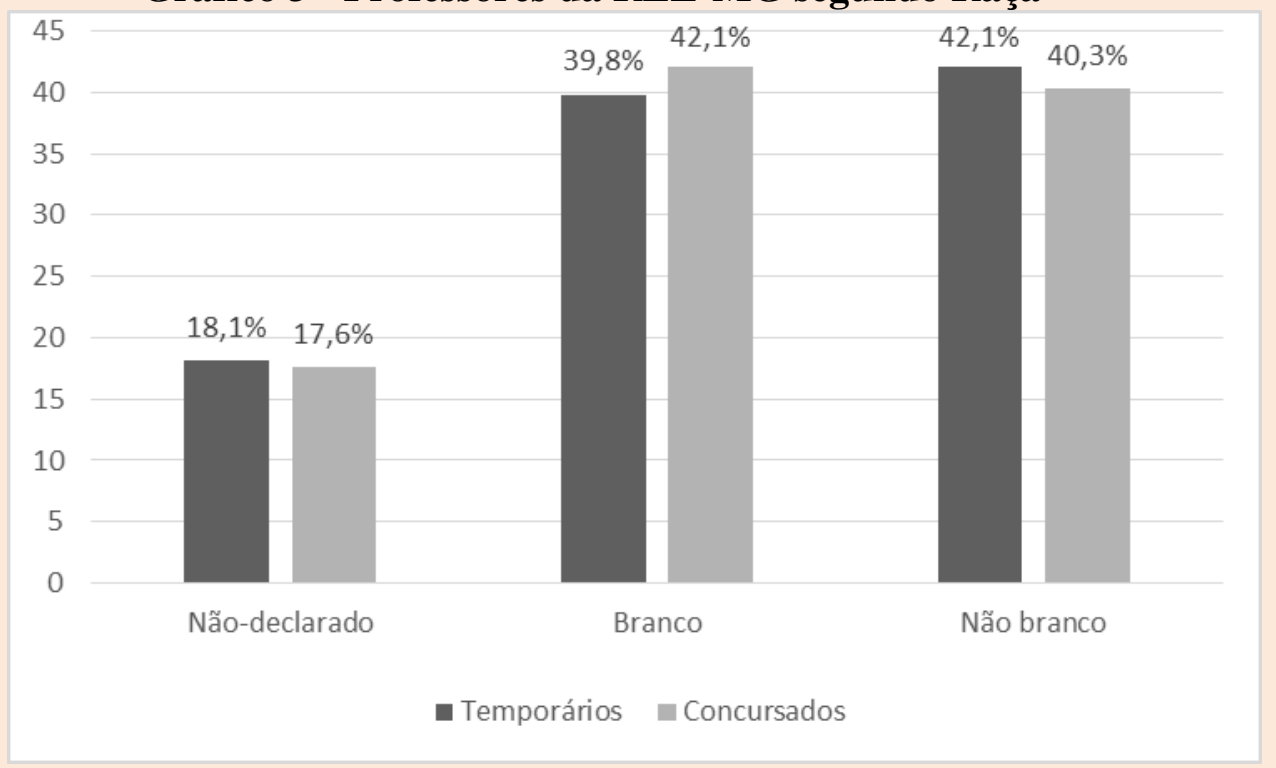

Obs.: Branca $=$ branca e amarela; Não-Branca = preta, parda e indígena.

Fonte: Elaborado pela autora a partir dos dados do Censo Escolar do INEP 2015.

No perfil do professor brasileiro, Gatti e Barretto (2009) 
identificaram um maior número de professores autodeclarados nãobrancos entre os docentes do ensino infantil e do Ensino Fundamental. Segundo as pesquisadoras, a desigualdade na escolaridade entre brancos e não-brancos e o acesso ainda limitado dos estudantes não-brancos ao ensino superior podem explicar a maior facilidade desses em entrar na profissão docente, especialmente nos anos iniciais do ensino. A diferença entre os grupos de professores concursados e temporários de Ensino Fundamental e Ensino Médio da REE-MG é pequena, mas vale destacar que tanto os dados dos concursados como os dos temporários sugerem a relevância da profissão docente como uma forma da inserção no mercado de trabalho por indivíduos não-brancos.

Em relação à idade dos docentes, é possível identificar uma diferença significativa entre temporários e concursados. Observa-se que a porcentagem de professores temporários é maior entre os profissionais mais jovens: 23,2\% com idade até 29 anos (em contraste com apenas 3\% de concursados nessa mesma faixa etária) e 32,8\% com idade entre 30 e 37 anos (contra $20 \%$ de professores concursados). Por outro lado, quase metade dos professores concursados (compostos, neste estudo, por efetivos e efetivados) encontra-se na faixa etária composta por professores de 46 anos ou mais. Isso pode ser um indicativo de que, caso não haja efetivação de novos professores por meio de concursos públicos, o número de professores concursados diminuirá ainda mais, pois eles são os mais próximos da aposentadoria. Ou seja, os profissionais com contratos estáveis são mais velhos em comparação aos que possuem contratos temporários e tendem a deixar a REE-MG no curto e médio prazo. 


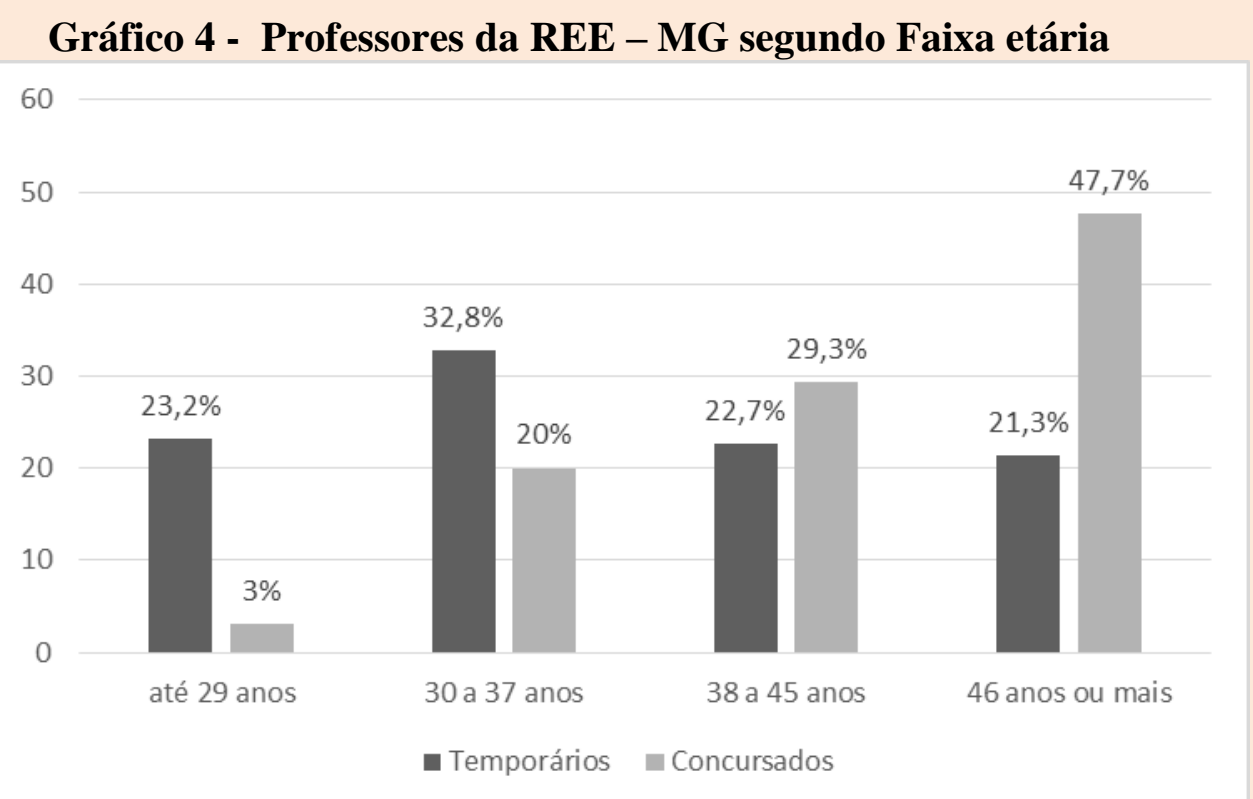

Fonte: Elaborado pela autora a partir dos dados do Censo Escolar do INEP 2015.

Os dados sobre faixa etária podem ser vistos com um misto de otimismo, relacionado ao fato de que deverá haver nos próximos anos uma renovação na força de trabalho docente nas escolas, abrindo uma oportunidade para melhorar os quadros da REE-MG, e de temor, já que a carreira docente atrai cada vez menos jovens qualificados (GATTI et al., 2009; GATTI ; BARRETTO, 2009), o que oferece um desafio crítico para os elaboradores de políticas públicas. Vale ressaltar que essa é uma preocupação também em outros países. A OCDE (2005) enfatiza a importância da elaboração de políticas que atraiam bons profissionais para trabalhar como docentes, pois os indicadores apontam que na maioria dos países do grupo a carreira docente também tem atraído um número cada vez menor e menos qualificado de candidatos. Por outro lado, os docentes trabalhando atualmente estão envelhecendo e irão se aposentar, o que exigirá a contratação de novos professores.

\subsection{Escolaridade}

No formulário preenchido pelos professores para o Cadastro do Profissional em Sala de Aula do Censo Escolar do INEP, os dados 
relativos à escolaridade identificam se o professor possui Ensino Fundamental incompleto, Ensino Fundamental completo, Ensino MédioNormal/Magistério Específico Indígena, Ensino Médio ou Ensino Superior. Nesse quesito, os dados apontam que há diferenciação entre os professores temporários e os concursados: $98 \%$ dos professores com contrato estável cursaram o Ensino Superior contra 89,2\% dos professores temporários.

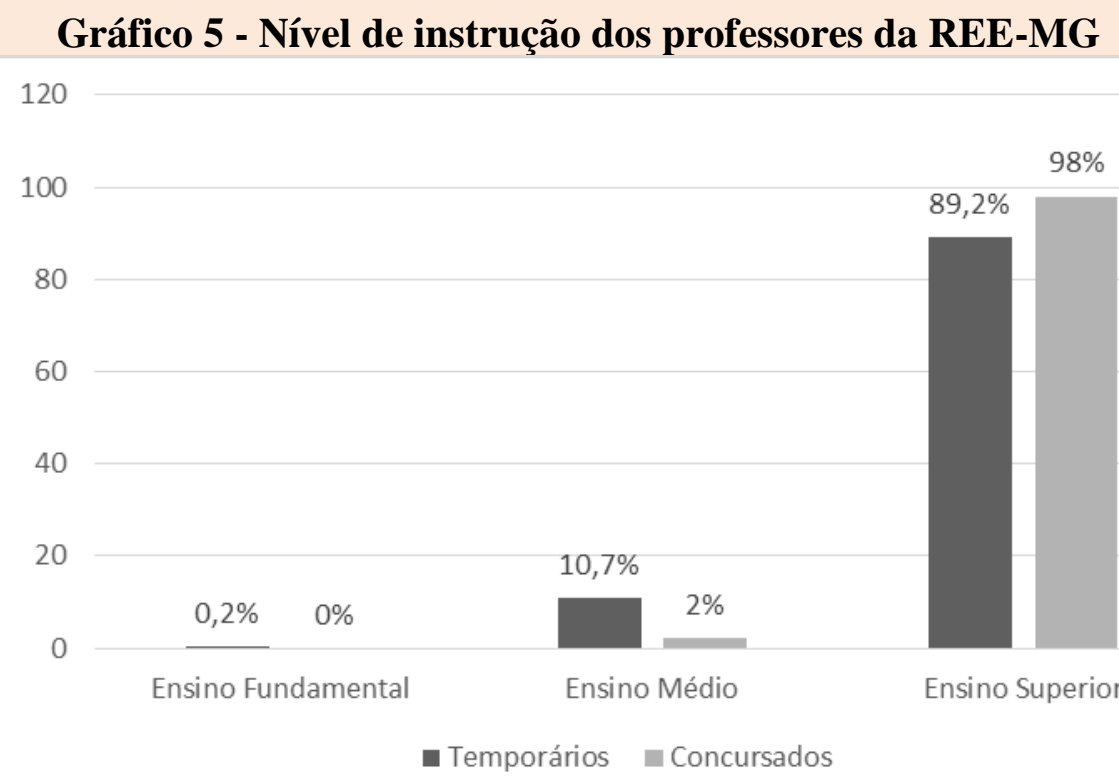

Fonte: Elaborado pela autora a partir dos dados do Censo Escolar do INEP 2015.

Os respondentes que assinalam a opção "ensino superior" para sua formação, devem, no item seguinte, especificar a situação do curso superior, identificando se o curso já foi concluído ou está em andamento. Dentre os docentes concursados, 99,3\% já haviam concluído o curso de ensino superior, sendo que essa porcentagem é de $93,8 \%$ para agrupamento de docentes temporários. Os dados indicam, portanto, que a ampla maioria dos professores da REE-MG tem formação em nível superior, o que, em termos absolutos, pode ser compreendido como um dado positivo.

A instituição de ensino superior frequentada pelos professores da REE-MG também pode ser identificada por meio da análise dos dados do Censo Escolar. Nesse item, o perfil de professores concursados e 
temporários apresenta bastante semelhança. Entre os concursados, $75 \%$ frequentaram ou frequentam uma instituição privada e $24,1 \%$ formaramse ou estão cursando a graduação em instituição pública. Os temporários se dividem entre $78,7 \%$ de alunos de instituições privadas e $21,3 \%$ de instituições públicas.

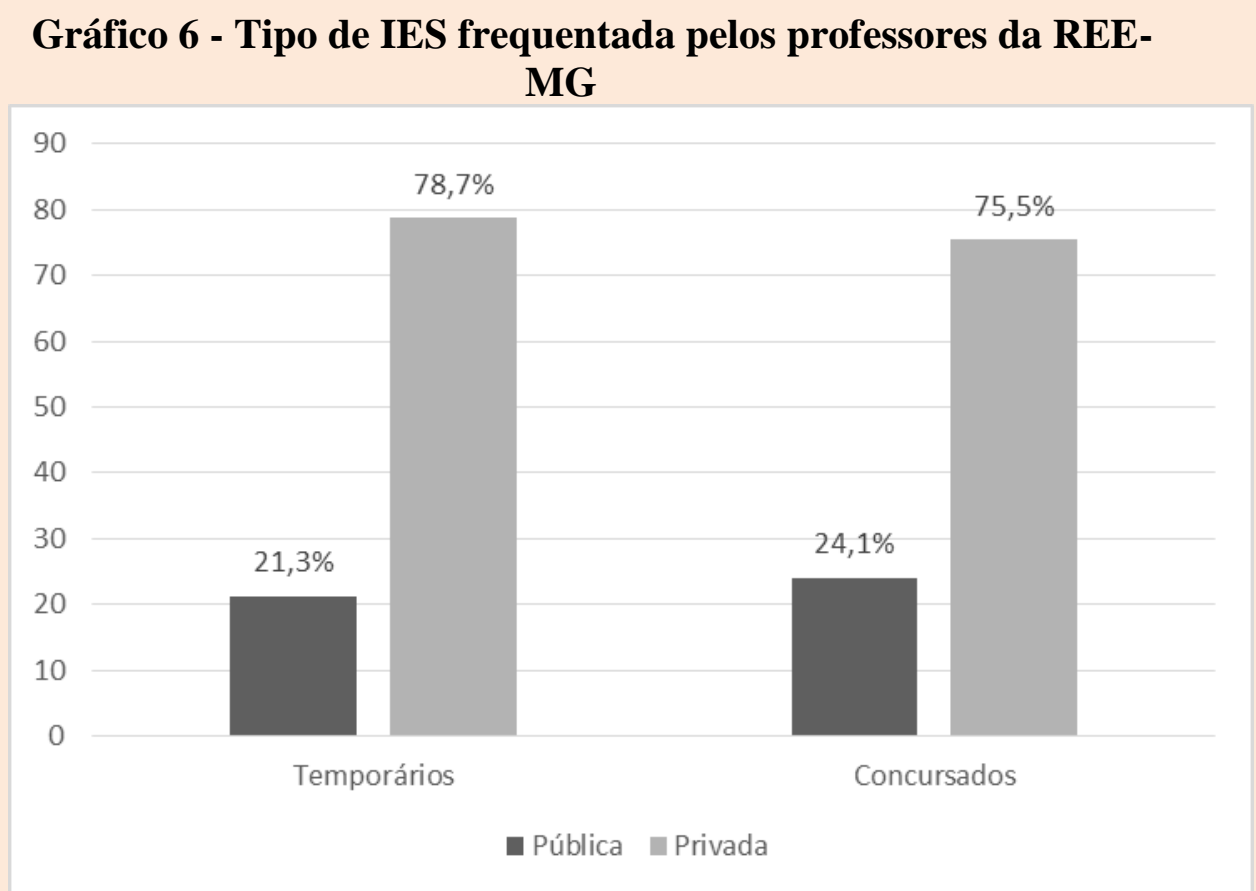

Fonte: Elaborado pela autora a partir dos dados do Censo Escolar do INEP 2015.

Esses dados corroboram outros levantamentos que mostram que a maioria dos professores da educação básica pública no país é formada em instituições privadas de ensino superior (BROOKE; CUNHA, 2012; BATISTA, 2007). Apesar do alto número de professores frequentando ou já tendo concluído um curso superior, é necessário observar características específicas sobre os perfis dos estudantes e dos cursos que frequentam e como se dá essa formação.

Os dados do Censo também permitem a identificação da taxa de frequência dos docentes da REE-MG a cursos de pós-graduação. Observando o gráfico 7, é possível perceber uma diferença importante entre o perfil de professores concursados e temporários: $48,1 \%$ de professores concursados têm algum diploma de pós-graduação, contra 
$25,2 \%$ dos profissionais temporários.

Gráfico 7 - Docentes fizeram curso de pós-graduação?

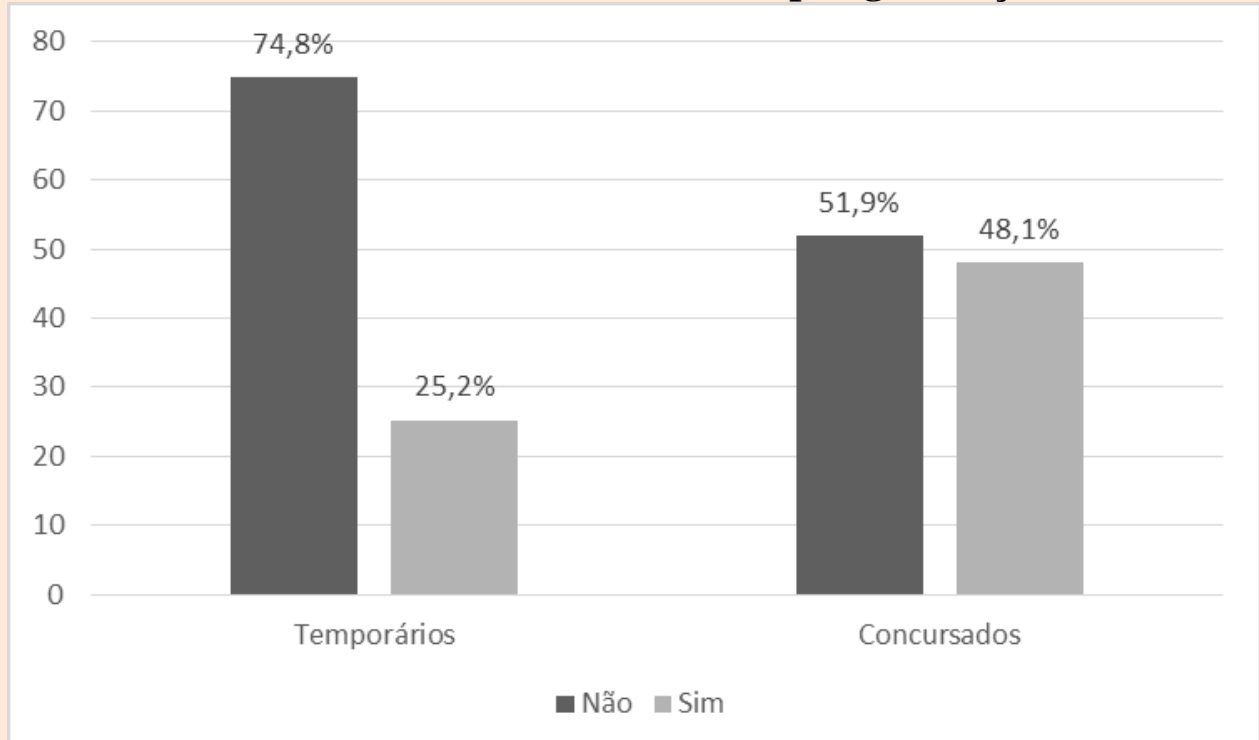

Fonte: Elaborado pela autora a partir dos dados do Censo Escolar do INEP 2015.

O número mais elevado de professores temporários sem um diploma de pós-graduação pode ser justificado se levarmos em consideração que eles são mais jovens e têm uma carreira menos estruturada. $\mathrm{Na}$ verdade, o precário vínculo de trabalho poderia ser uma explicação para os menores investimentos dos professores temporários em uma formação continuada. Outra hipótese é que os docentes concursados tendam a fazer maiores investimentos em cursos de pósgraduação, já que, em princípio, têm uma vida profissional como docentes mais longa, são funcionários públicos efetivos e possuem alguns incentivos à formação continuada em seus planos de carreira.

Outra questão relevante sobre escolaridade relaciona-se ao tipo de curso de pós-graduação em que os docentes da REE-MG investem. Dentro do grupo de docentes concursados que fez um curso de pósgraduação, 97,4\% fez algum curso de especialização e o restante fez curso de mestrado ou doutorado. A porcentagem é a mesma para os professores temporários que fizeram alguma pós-graduação: 97,4\% deles participou de algum curso de especialização e os outros 2,6\% se dividiram entre cursos de mestrado ou doutorado. Esse é um dado que 
merece destaque, já que as pesquisas sobre efeito-professor indicam uma relação positiva entre cursos de formação continuada e melhora no desempenho dos alunos. Como apresentado no item 2 deste artigo, os estudos sobre efeito-professor não conseguiram estabelecer uma relação entre cursos de pós-graduação stricto sensu, ou seja, mestrado e doutorado, e maior eficácia do professor (RIVKIN, HANUSHEK; KAIN, 2005). Portanto, nesse sentido, os investimentos dos docentes da REEMG em formação continuada parecem estar indo na direção adequada para aprimorar suas práticas.

\subsection{Algumas características do trabalho docente}

Apesar de não ser possível mensurar diretamente o esforço empreendido pelos professores no exercício de sua profissão, o indicador de esforço docente (INSTITUTO NACIONAL DE ESTUDOS E PESQUISAS EDUCACIONAIS ANÍSIO TEIXEIRA, 2014) leva em consideração um conjunto de variáveis entendidas como definidoras do esforço do trabalho docente, a saber: 1. Número de escolas em que o professor atua; 2. Número de turnos de trabalho; 3. Número de alunos atendidos; 4. Número de etapas em que o docente. A partir da análise desses itens, o INEP propôs uma escala de esforço da atividade docente que apresenta uma estimativa do esforço do professor em sua atividade e o posiciona entre o conjunto dos docentes. Essa escala é composta por 6 níveis, distribuídos da seguinte maneira: 


\section{Quadro 1 - Níveis de esforço docente}

\begin{tabular}{|c|c|}
\hline Níveis & Descrição \\
\hline Nível 1 & $\begin{array}{l}\text { Docente que tem até } 25 \text { alunos e atua em } \\
\text { um único turno, escola e etapa de ensino. }\end{array}$ \\
\hline Nível 2 & $\begin{array}{l}\text { Docente que tem entre } 25 \text { e } 150 \text { alunos e } \\
\text { que atua em um único turno, escola e } \\
\text { etapa de ensino. }\end{array}$ \\
\hline Nível 3 & $\begin{array}{l}\text { Docente que tem entre } 25 \text { e } 300 \text { alunos e } \\
\text { que atua em um ou dois turnos, em uma } \\
\text { única escola e etapa de ensino. }\end{array}$ \\
\hline Nível 4 & $\begin{array}{l}\text { Docente que tem entre } 50 \text { e } 400 \text { alunos e } \\
\text { atua em dois turnos, em uma ou duas } \\
\text { escolas e em duas etapas de ensino. }\end{array}$ \\
\hline Nível 5 & $\begin{array}{l}\text { Docente que tem mais de } 300 \text { alunos e } \\
\text { atua nos três turnos, em duas ou três } \\
\text { escolas e em duas ou três etapas de } \\
\text { ensino. }\end{array}$ \\
\hline Nível 6 & $\begin{array}{l}\text { Docente que tem mais de } 400 \text { alunos e } \\
\text { atua nos três turnos, em duas ou três } \\
\text { escolas e em duas ou três etapas de } \\
\text { ensino. }\end{array}$ \\
\hline
\end{tabular}

Fonte: (INEP, 2014)

Este artigo não pretende apresentar o índice do esforço docente para a REE, porém, acreditamos que a apresentação de alguns dos dados que compõem o índice pode enriquecer o perfil traçado aqui. Dentre essas variáveis, serão discutidos dados sobre o número de escolas, número de turnos e média de alunos por professor. Como a pesquisa investigou apenas professores de Ensino Fundamental e de Ensino Médio da REE-MG, não foi feita diferenciação por etapa de ensino e, por isso, não foram incluídos dados sobre o número de etapas em que o docente atua. 
Em relação ao número de escolas em que o professor da REE-MG atua, a grande maioria dos professores da REE-MG trabalha em apenas uma instituição. Os números são bastante semelhantes tanto para professores concursados quanto para temporários: $87,3 \%$ dos professores temporários e $85,5 \%$ dos professores concursados atuam em apenas uma escola. Como os dados desta pesquisa referem-se apenas à REE-MG não é possível saber se esses docentes atuam também em escolas de outras redes de ensino. De qualquer forma, dentro da REE-MG, a quase totalidade dos docentes atua em, no máximo, dois estabelecimentos de ensino.

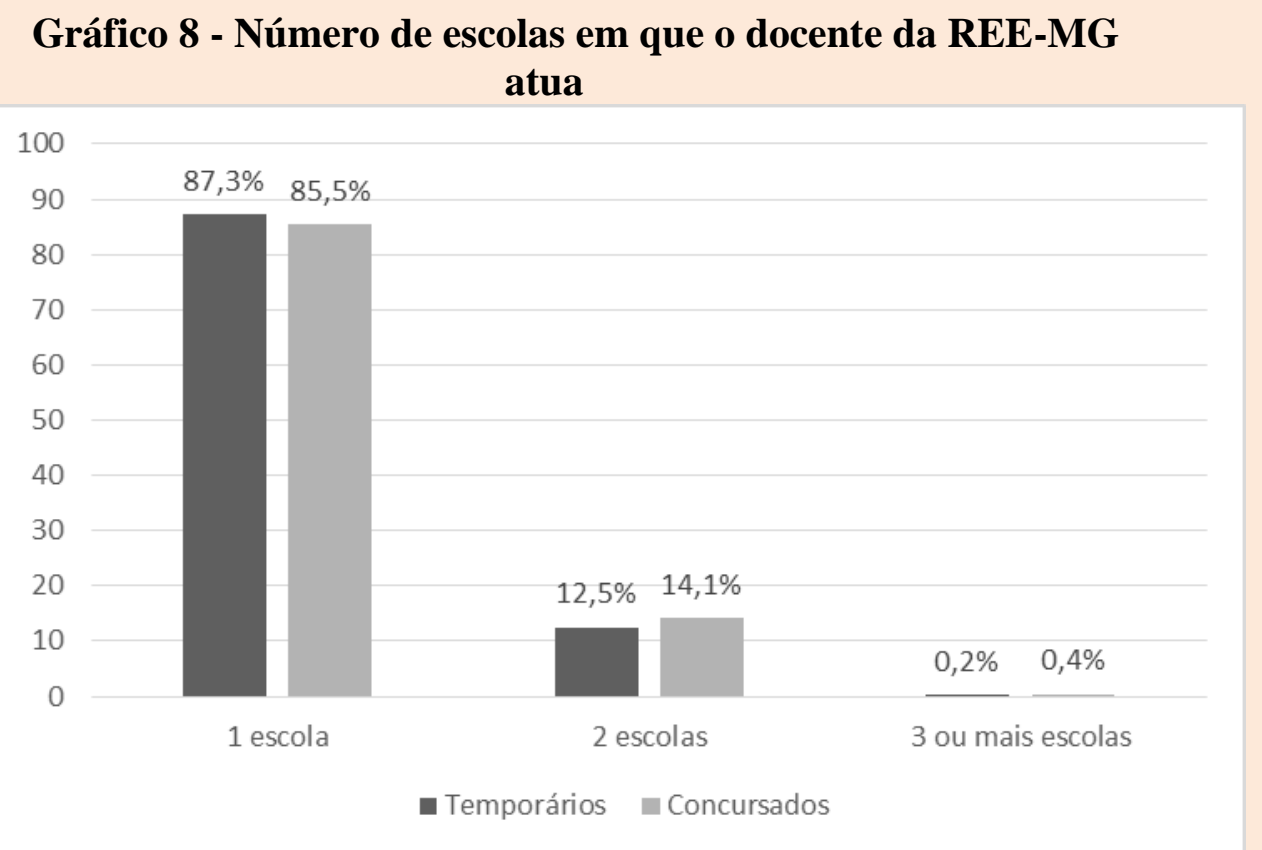

Fonte: Elaborado pela autora a partir dos dados do Censo Escolar do INEP 2015

No que tange ao número de turnos em que os docentes atuam, apesar de a maioria dos professores trabalhar em apenas um turno, os dados apresentam alguma diferenciação entre concursados e temporários. Existem mais professores temporários trabalhando em apenas um turno do que professores efetivos: são $64 \%$ de temporários e 56,4\% de efetivos. Por outro lado, há mais professores efetivos lecionando em dois turnos do que professores temporários: $37,9 \%$ de professores efetivos contra $31 \%$ de professores temporários. O dado em si, é positivo. Porém, vale 
ressaltar que este estudo levou em consideração apenas a REE-MG e que os professores podem trabalhar também em outras redes de ensino. Além disso, como são professores contratados para substituir docentes efetivos que, por algum motivo, estão afastados, possivelmente, os professores temporários não possuem uma carga horária mínima de trabalho e tenderiam trabalhar em apenas um turno.

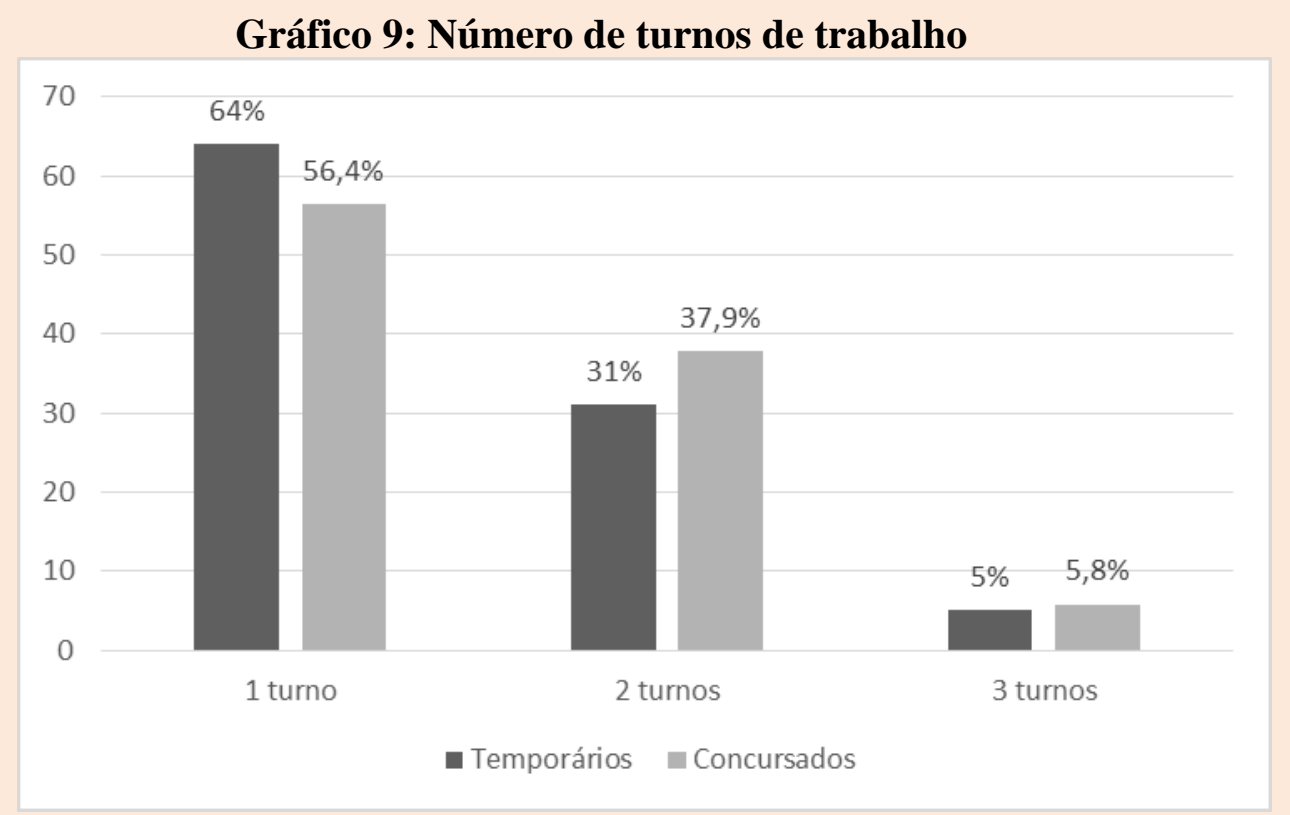

Fonte: Elaborado pela autora a partir dos dados do Censo Escolar do INEP 2015

Quanto ao número de alunos por professor, foram usadas como referência as seis faixas estipuladas no índice do esforço docente: até 15 alunos, entre 26 e 50 alunos, entre 51 e 150 alunos, entre 151 e 300 alunos, entre 301 e 400 alunos e mais de 400 alunos. Como pode ser observado no gráfico 10, os professores concursados têm um número maior de alunos: mais de $60 \%$ dos professores efetivos possuem ente 51 e 300 alunos. 


\section{Gráfico 10 - Média de número de alunos por professor}

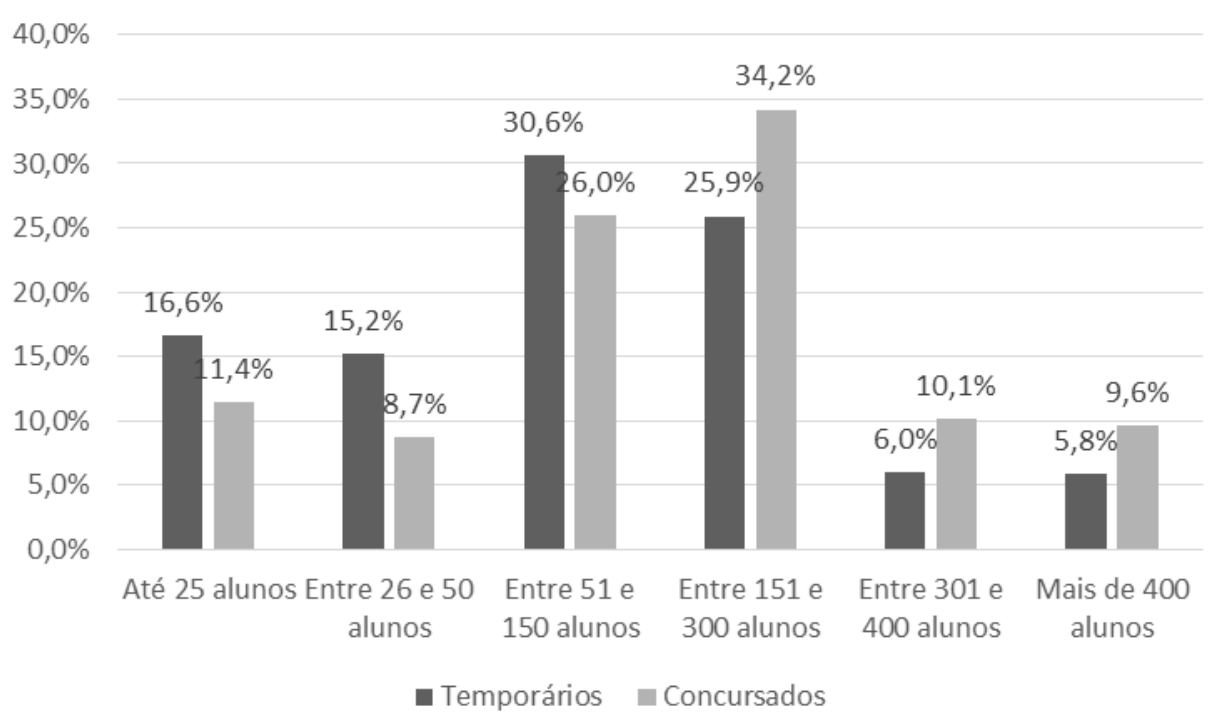

Fonte: Elaborado pela autora a partir dos dados do Censo Escolar do INEP 2015

Vale lembrar que, para além do número total de estudantes atendidos por um docente, o número de alunos em uma única sala de aula afeta diretamente o trabalho do professor e a aprendizagem dos alunos. Uma coisa é ter 180 alunos distribuídos em 4 turmas distintas, o que daria uma média de 45 alunos por classe; outra é ter os mesmos 180, mas em 5 turmas, tendo uma média de 36 alunos. De acordo com Tardif e Lessard (2014), o número de estudantes por sala é uma questão importante, não somente porque um número menor de alunos torna menor a carga de trabalho do docente, mas sobretudo porque os professores podem dar uma atenção mais individualizada para os alunos.

\section{CONSIDERAÇÕES FINAIS}

Alguns aspectos da análise apresentada aqui merecem destaque. $\mathrm{O}$ primeiro está relacionado à idade média dos docentes. Como discutido, nos próximos anos, a REE-MG deverá passar por uma renovação do seu quadro de professores, o que indica uma oportunidade para refletir sobre a contratação e o plano de carreira dos docentes. Como atrair e reter bons docentes na REE-MG? Essa é uma questão central sobre a qual gestores e elaboradores de políticas públicas devem se debruçar para propor 
encaminhamentos de ações de políticas públicas que priorizem a qualidade dos docentes e do ensino e que possam impactar positivamente a aprendizagem dos alunos.

Outro ponto a ser ressaltado é a grande porcentagem de professores que se autodeclara não-brancos. A escolha pela profissão docente por indivíduos não-brancos pode ser considerada uma escolha livre ou foi feita com base em um senso prático que fez com que eles ajustem suas expectativas e "escolhessem" cursos de graduação menos seletivos e valorizados como as licenciaturas, que, por sua vez, os conduziram a profissões, também de menor prestígio? Essa inserção mais igualitária de não-brancos no mercado de trabalho docente não esconderia, na verdade, uma exclusão? Esse é um dado que merece uma análise mais aprofundada em outros estudos.

Em relação à escolaridade dos professores, a formação em nível superior não parece ser mais um problema crítico. A ampla maioria dos professores concursados e temporários possui curso superior e uma parcela significativa de professores investe em formação no nível de pósgraduação. É importante observar que as IES frequentadas por esses docentes são, em sua maioria, privadas, o que pode sugerir uma formação menos sólida. Gatti e Barretto (2009) identificaram que, no Brasil, 54\% dos estudantes de licenciatura tem idade superior a 24 anos e $74 \%$ trabalha parcial ou integralmente, o que sugere que as condições objetivas vividas por eles não favorecem uma trajetória escolar favorável no meio acadêmico, já que não poderão se dedicar integralmente aos estudos. De acordo com as pesquisadoras, a maior parte dos estudantes $(50,4 \%)$ possui faixa de renda média de 3 a 10 salários mínimos, mas existe uma inflexão para a faixa de renda mais baixa, de 1 a 3 salários mínimos $(39,2 \%)$. Ainda segundo os dados levantados pelas autoras, os alunos possuem pouca familiaridade/identificação com as práticas que seriam consideradas adequadas para o contexto escolar - como a leitura e o uso da biblioteca. Portanto, a questão que agora se coloca é como tem se dado essa formação em nível superior. 
Tirar conclusões precisas dos dados sobre o trabalho docente aqui apresentado seria arriscado, já que muitos outros aspectos poderiam e deveriam ser levados em consideração para um cenário mais completo sobre o tema, como salário, carga horária de trabalho, número de alunos por turma, dentre outros. Além disso, o perfil apresentado não leva em consideração o trabalho em outras redes de ensino e o perfil do docente aqui descrito pode sofrer incrementos em seu trabalho se atuar em escolas municipais ou particulares, o que não é incomum. Porém, dentro da REE-MG, os seguintes pontos podem ser ressaltados em relação às características do trabalho docente: a maioria dos professores efetivos trabalha em apenas uma escola da rede, em não mais de dois turnos e possui entre 151 e 300 alunos. O perfil é bastante semelhante ao dos professores temporários, com a diferença que uma porcentagem maior de docentes temporários possui um número menor de alunos - entre 51 e 150 , muito provavelmente por terem menos turmas que os professores concursados.

Tendo em vista os reflexos positivos que um bom professor pode gerar para a aprendizagem dos alunos, o perfil traçado neste artigo contribui para ampliar a compreensão sobre quem são os docentes da REE-MG e fornecer subsídios para a elaboração de políticas públicas que visem a valorização dos docentes e a melhoria da educação no estado de Minas Gerais.

\section{REFERÊNCIAS}

AMORIM, Marina Alves; BARREIROS, Brenda Cambraia.

Superdesignação de professores na rede estadual de ensino de Minas Gerais. [S.1.: s.n.], 2017. No prelo.

BATISTA, Antonio G. As invasões bárbaras: os benefícios sociais, econômicos e culturais da escolarização longa. Relatório parcial de pesquisa. Belo Horizonte: Faculdade de Educação, UFMG, 2007. Disponível em:

<http://sites.google.com/site/posfaeantoniobatista/arquivos〉.

BOURDIEU, Pierre. A sociologia de Pierre Bourdieu. ORTIZ, Renato 
(Org.). São Paulo: Olho d'Água, 2003.

BOURDIEU, Pierre. Os excluídos do interior. In: NOGUEIRA, Maria Alice; CATANI, Afrânio (Org.). Escritos de educação. Petrópolis, RJ: Vozes, 2008.

BRASIL. Ministério da Educação Brasil no PISA 2015: análises e reflexões sobre o desempenho dos estudantes brasileiros / OCDEOrganização para a Cooperação e Desenvolvimento Econômico. São Paulo: Fundação Santillana, 2016.

BRASIL. Ministério da Educação IDEB: resultados e metas. Brasília: MEC, 2016. Disponível em:

$<$ http://ideb.inep.gov.br/resultado/resultado/resultadoBrasil.seam?cid=38 86819>. Acesso em: 07dez. 2016.

BRASIL. Ministério da Educação Planejando a próxima década: conhecendo as 20 metas do Plano Nacional de Educação. Brasília: Ministério da Educação, 2014. 62p.

BRASIL. Ministério da Educação Projeto de lei. Aprova o Plano Nacional de Educação 2011-2020 e dá outras providências. Brasília: MEC, 2010. Disponível em: <https://www.camara.gov.br/sileg/integras/831421.pdf >. Acesso em: 04 out. 2017.

BRASIL. Ministério da Educação Relatório educação para todos: versão preliminar. Brasília: MEC, 2015.

BRESSOUX, Pascal. As pesquisas sobre o efeito-escola e o efeitoprofessor. Educação em Revista, Belo Horizonte, n. 38, 2003.

BROOKE, Nigel; SOARES, José Francisco. Pesquisa em eficácia escolar: origem e trajetórias. Belo Horizonte: Editora UFMG, 2008.

BROOKE, Nigel; CUNHA, Maria Amália. (Org.). Professores dos anos iniciais: perfis em mudança. Belo Horizonte, MG: Fino Traço, 2012.

CHETTY, Raj; FRIEDMAN, John N.; ROCKOFF, Jonah E. The longterm impacts of teachers: teacher value-added and student outcomes in adulthood. Cambridge: National Bureau of Economic Research, 2011. (Working Paper series, number 17699).

DARLING-HAMMOND, Linda. Teacher Quality And Student Achievement. Education Policy Analysis Archives, v. 8, num. 1, jan.2000. 
GATTI, Bernadete. A.; BARRETTO, Elba de Sá. Professores do Brasil: impasses e desafios. Brasília: UNESCO, 2009.

GATTI, Bernadete. A.; BARRETTO, Elba de Sá; ANDRÉ, Marli.

Políticas docentes no Brasil: um estado da arte. Brasília: UNESCO, 2011.

GATTI, Bernadette et al. A atratividade da carreira docente no Brasil. São Paulo: Fundação Carlos Chagas, 2009. Disponível em:

$<$ http://revistaescola.abril.com.br/pdf/relatorio-final-atratividade-carreiradocente.pdf >. Acesso em: 02 out. 2017.

HANUSHEK, E. Schooling, labor force quality, and the growth of nations. American Economic Review, 90(5), 1184-1208, 2002.

INSTITUTO NACIONAL DE ESTUDOS E PESQUISAS EDUCACIONAIS ANÍSIO TEIXEIRA. Nota técnica no 039/2014: indicador de esforço docente. Brasília: MEC, 2014. Disponível em: < http://download.inep.gov.br/informacoes_estatisticas/indicadores_educac ionais/2014/docente_esforco/nota_tecnica_indicador_docente_esforco.pd f>. Acesso em: 04 out. 2017.

MINAS GERAIS. Lei Complementar $\mathrm{n}^{\circ} 100$, de 05 de novembro de 2007. Institui a Unidade de Gestão Previdenciária Integrada - Ugeprevi do Regime Próprio de Previdência dos Servidores Públicos do Estado de Minas Gerais[...]Diário do Executivo, Belo Horizonte, 05 nov. 2007. Disponível em: <

https://www.almg.gov.br/consulte/legislacao/completa/completa.html?tip $\mathrm{o}=\mathrm{LCP} \&$ num $=100 \& a \mathrm{no}=2007 \& \mathrm{aba}=\mathrm{js} \_$textoAtualizado $>$. Acesso em: 04 out. 2017.

ORGANIZAÇÃO PARA A COOPERAÇÃO E DESENVOLVIMENTO ECONÔMICO. Teachers matter: attracting, developing and retaining effective teachers. Paris: OCDE, 2005.

RIVKIN, Steven G.; HANUSHEK, Eric A., KAIN, John F. Teachers, schools, and academic achievement. Econometrica, v. 73, n. 2, p. 417458, mar, 2005.

SILVA, Luciano Campos da; MATOS, Daniel Abud Seabra. As percepções dos estudantes mineiros sobre a incidência de comportamentos de indisciplina em sala de aula: um estudo a partir dos dados do SIMAVE/PROEB. In: REUNIÃO ANUAL DA ANPED, 35. 2012. Porto de Galinhas, PE. Anais... Porto de Galinhas, PE: ANPED, out. 2012. Disponível em: <2007http://35reuniao.anped.org.br/images/stories/trabalhos/GT14\%20T rabalhos/GT14-1472_int.pdf>. Acesso em: 02 out. 2017. 
TARDIF, Maurice; LESSARD, Claude. O trabalho docente: elementos para uma teoria da docência como profissão de interações humanas.

Petrópolis, RJ: Vozes, 2014. 